\title{
Histone DEMETHylases JHDM1D, PHF2 AND PHF8 EXPRESSION PATTERN IN GRANULOSA CELLS OBTAINED FROM PATIENTS UNDERGOING IVF PROCEDURE DURING SHORT-TERM IVC
}

Rut Bryl ${ }^{1}$, Katarzyna Stefańska², Błażej Chermuła ${ }^{3}$, Bogumiła Stelmach ${ }^{3}$, Wojciech Pieńkowski ${ }^{4}$, Jakub Kulus ${ }^{5}$, Joanna Perek ${ }^{1}$, Maria Wieczorkiewicz ${ }^{6}$, Grzegorz Wąsiatycz ${ }^{7}$, Kornel Ratajczak ${ }^{7}$, Leszek Pawelczyk ${ }^{3}$, Paul Mozdziak ${ }^{8}$, Michal Jeseta ${ }^{9}$, Robert Z. Spaczyński ${ }^{3}$, Dorota Bukowska ${ }^{5}$

\begin{abstract}
Granulosa cells play an important role in follicle development, maturation, and atresia. They are a cellular source of the two most important ovarian steroids, namely, estradiol and progesterone and are also crucial for bidirectional communication with the oocyte, thus being involved in the regulation of its growth, development and function. Growing body of evidence suggests that granulosa cells cultured in vitro display stemness and transdifferentiation potential. Together with the fact that they can be easily collected during IVF procedures, these properties of GCs may be of particular interest for both regenerative medicine and transplantology. Establishment of in vitro cell culture and its thorough characterization, including molecular, is crucial for future potential utilization of human granulosa cells in design of engineered tissue grafts or cell-based therapies, in particular targeted at female infertility. Nevertheless, the transcriptomic alterations which may occur during in vitro culture of granulosa cells are still largely uncharacterized. The aim of this study was to examine expression changes of three genes encoding histone demethylases which serve as transcription coactivators in short term in vitro cell culture of human granulosa cells. The study groups consisted of 14 patients, aged 18-40 years undergoing in vitro fertilization (IVF). Expression level assessment was performed after 24 h, 48 h, 72 h, 96 h, 120 h, $144 \mathrm{~h}$ and $168 \mathrm{~h}$ of in vitro primary cell culture utilizing RT-qPCR technique. Upregulation of PHF2 expression in all time points of the culture was observed, whereas the tendency of $J H D M 1 D$ and $P H F 8$ was mainly to decrease in expression level. Further study on a larger population would be required in order to confirm the presented tendencies.
\end{abstract}

Running title: Expression pattern of selected histone demethylases in human granulosa cells

Keywords: human granulosa cells, GCs, histone demethylases, epigenetic changes, expression level, short-term in vitro cell culture

\footnotetext{
${ }^{1}$ Department of Anatomy, Poznan University of Medical Sciences, Poznań, Poland

${ }^{2}$ Department of Histology and Embryology, Poznań University of Medical Sciences, Poznań, Poland

${ }^{3}$ Division of Infertility and Reproductive Endocrinology, Department of Gynecology, Obstetrics and Gynecological Oncology, Poznań University of Medical Sciences, Poznań, Poland

${ }^{4}$ Division of Perinatology and Women's Diseases, Poznń University of Medical Sciences, Poznań, Poland

${ }^{5}$ Department of Diagnostics and Clinical Sciences, Institute of Veterinary Medicine, Nicolaus Copernicus University in Toruń, Toruń, Poland

${ }^{6}$ Department of Basic and Preclinical Sciences, Institute of Veterinary Medicine, Faculty of Biological and Veterinary Sciences, Nicolaus Copernicus University in Toruń, Toruń, Poland.

${ }^{7}$ Department of Veterinary Surgery, Institute of Veterinary Medicine, Nicolaus Copernicus University in Toruń, Toruń, Poland

${ }^{8}$ Physiology Graduate Program, North Carolina State University, Raleigh, NC, USA

*Correspondence: dbukowska@umk.pl

Full list of author information is available at the end of article
} 


\section{Introduction}

Granulosa cells (GCs) among the ovarian surface epithelium and the theca cells are one of three somatic cell types involved in folliculogenesis regulation. They accompany the oocyte during the last phase of preovulatory follicle growth, residing within the ovarian follicle's avascular space $[1,2]$. Mural GCs are involved in estrogen production in follicular phase and progesterone production after ovulation [3]. They play an important role in bidirectional communication with the oocyte regulating its growth, development and function [4,5].

It has been numerously reported that GCs cultured in vitro display stem-like potential and may be capable of differentiation into specialized cell types such as chondrocytes, neurons, muscle cells, cardiomyocytes and osteoblasts under appropriate conditions [6-9]. These unique properties, together with ease of collection during routine assisted reproductive technology procedures, make granulosa cells an attractive source of stem cells for applications in reconstructive and regenerative medicine. Furthermore, as adult cells, they are devoid of limitations specific to embryonic stem cells such as risk of teratoma formation, immune rejection and ethical controversies $[10,11]$.

Epigenetics is a discipline which aims at studying heritable gene expression changes independent of DNA sequence but are rather influenced by DNA methylation, chromatin modification and non-coding RNAs[12,13]. JHDM1D (also known as KIAA1718 or KDM7A), PHF2, and PHF8 belong to a Jumonji C domain-containing (JmjC) family of proteins and can remove the methylation of H3K9, H3K27 and H4K20. Therefore, this 3 histone demethylases serve as transcription coactivators [14-16].

The establishment and molecular characterization of in vitro human granulosa cell culture may be of great importance for the future regenerative medicine applications, such as design of engineered tissue grafts or cell-based therapies for the treatment of female infertility [17].

The aim of this study was to characterize the expression levels of three genes encoding histone demethylases in short term in vitro cell culture of human granulosa cells in six time points: $48 \mathrm{~h}, 72$ h, $96 \mathrm{~h}, 120 \mathrm{~h}, 144 \mathrm{~h}, 168 \mathrm{~h}$ in reference to $24 \mathrm{~h}$ by utilization of RT-qPCR technique.

\section{Material and Methods \\ Patients and collection of GCs}

Granulosa cells were obtained from patients undergoing in vitro fertilization (IVF) who had given their informed consent to be involved in the research. The study group included 14 patients, aged 18-40 years. Individuals with risk of inadequate ovarian stimulation were excluded from the study, according to Bologna's criteria of poor ovarian responders published by the European Society of Hu- man Reproduction and Embryology (ESHRE) (serum antimullerian hormone (AMH) level of $0.7 \mathrm{ng} /$ $\mathrm{mL}$ was used as a cut-off value) [18]. Patients with polycystic ovary syndrome (PCOS), endometriosis, who displayed day 2-3 FSH serum level higher than $15 \mathrm{mU} / \mathrm{mL}$, and/or antral follicle count less than 9 were also excluded. IVF procedures were carried out in the Department of Infertility and Reproductive Endocrinology, Poznan University of Medical Sciences, Poznan. Patients diagnosed with infertility where subjected to proceedings based on controlled ovarian hyperstimulation protocol. Recombinant FSH (Gonal-F, Merck Serono, Darmstadt, Germany) and highly purified human menopausal gonadotropin (hMG-HP, Menopur, Ferring, SaintPrex, Switzerland) were applied in order to stimulate ovarian response. For suppression of pituitary function, Cetrorelix Acetate (Cetrotide, Merck Serono, Darmstadt, Germany) injections in an adequate dose were administered. Subsequently, $6500 \mathrm{U}$ of human chorionic gonadotropin (hCG; Ovitrelle, Merck-Serono, Darmstadt, Germany) was injected subcutaneously to induce ovulation. After transvaginal, ultrasound-guided oocyte pick-up (OPU), the follicular fluid (FF) containing GCs from ovarian follicles larger than $16 \mathrm{~mm}$ was collected for the analysis.

For GCs separation and collection, FF samples were centrifuged at $250 \mathrm{xg}$ for $10 \mathrm{~min}$.

\section{Cell isolation and primary cell culture}

After first centrifugation, the supernatant was discarded and the pellet was resuspended in $5 \mathrm{ml}$ of Dulbecco's phosphate buffered saline (D-PBS; Sigma, St Louis, MO, USA). For cell separation, 15 $\mathrm{ml}$ falcon centrifuge tubes were filled with $6 \mathrm{ml}$ of Pancoll (PAN Biotech, Aidenbach, Germany) and the layer of the separating solution was covered with the layer of the tested sample. Next, the samples were centrifuged at $390 \mathrm{rcf}$ for 20 minutes and, afterwards, the top layer was transferred to a new 15 $\mathrm{ml}$ tube and resuspended in $5 \mathrm{ml}$ of culture medium consisting of: Dulbecco's Modified Eagle's Medium (DMEM; Sigma; Merck KGaA, Darmstadt, Germany), $10 \%$ fetal bovine serum FBS (FBS; Sigma; Merck KGaA, Darmstadt, Germany), 200 mM L-glutamine, $10 \mathrm{mg} / \mathrm{ml}$ gentamicin 10,000 units/ml penicillin, and $10,000 \mu \mathrm{g} / \mathrm{ml}$ streptomycin (Invitrogen; Thermo Fisher Scientific, Inc., Waltham, MA, USA). Subsequently, the centrifugation at $250 \mathrm{rcf}$ for 10 minutes was performed, the pellet was suspended in $5 \mathrm{ml}$ of the culture medium and the samples were centrifuged at $250 \mathrm{x}$ g for 5 minutes. The pellet was resuspended in $5 \mathrm{ml}$ of collagenase type II (Sigma Aldrich, St. Louis, MO, USA) solution in Dulbecco's modified Eagle's medium (c $=1 \mathrm{mg} / \mathrm{ml}$ ) and incubated at $37^{\circ} \mathrm{C}$ for 10 minutes with gentle shaking. The obtained cell suspension was filtered through a cell strainer and transferred to a new $15 \mathrm{ml}$ falcon centrifuge tubes. The samples were subjected to centrifugation at 250 
$\mathrm{x} g$ for 10 minutes, the pellet was resuspended in 4 $\mathrm{ml}$ of culture medium and the suspension was transferred to 25 bottle. The cell culture was maintained at $37^{\circ} \mathrm{C}$ in a humified atmosphere of $5 \% \mathrm{CO}_{2}$.

\section{RNA Extraction}

Total RNA was extracted after $24 \mathrm{~h}, 48 \mathrm{~h}, 72 \mathrm{~h}, 96 \mathrm{~h}$, $120 \mathrm{~h}, 144 \mathrm{~h}$ and $172 \mathrm{~h}$ of the cell culture, respectively. Firstly, the cells were washed with D-PBS, digested with $0.05 \%$ trypsin- ethylenediaminetetraacetic acid (trypsin - EDTA; Invitrogen; Thermo Fisher Scientific, Inc., Waltham, MA, USA) at $37^{\circ} \mathrm{C}$ for $1-2$ minutes, neutralized by culture medium and centrifuged at $200 \mathrm{rcf}$ for 5 minutes. The pellet was resuspended in $500 \mu \mathrm{l}$ of TRI Reagent Solution (TRI Reagent®, Sigma-Aldrich, St. Luis, MO, USA). The aliquots were stored in $-80^{\circ} \mathrm{C}$ until RNA isolation.

\section{RNA Isolation}

Total RNA was isolated according to the Chomczyński and Sacchi method [19]. Firstly, $150 \mu \mathrm{l}$ of chloroform was added, the samples were mixed by inversion and shaken for $15 \mathrm{sec}$ and then incubated for $10 \mathrm{~min}$ at RT. Subsequently, the biphasic emulsion was separated by centrifugation at 12500 rpm for $15 \mathrm{~min}$ at $4^{\circ} \mathrm{C}$. The aqueous phase which contained RNA was transferred to new Eppendorf tubes. Next, the isopropanol (Sigma-Aldrich, St. Luis, MO, USA, catalogue number I9516) was added (the volume was calculated according to the guidelines in the protocol: $250 \mu \mathrm{l}$ of isopropanol was added to 400 $\mu \mathrm{l}$ of aqueous phase), the samples were mixed by inversion and shaken for 15 seconds and incubated for 15 minutes at RT. The samples were centrifuged at $12500 \mathrm{rpm}$ for 8 minutes at $4^{\circ} \mathrm{C}$. $75 \%$ ethanol solution was added to the precipitate, the samples were vortexed, centrifuged at $7500 \mathrm{x}$ g for $15 \mathrm{~min}$ at $4^{\circ} \mathrm{C}$. The supernatant was discarded, the samples were air-dried and dissolved in $13 \mu \mathrm{l}$ of PCR-grade water.

The spectrophotometric analysis at $\lambda=260 \mathrm{~nm}$ was performed (NanoDrop spectrophotometer; Thermo Fisher Scientific, Waltham, MA, USA) in order to assess the concentration and quality of the samples.

\section{RT-qPCR (reverse transcription - quantitative polymerase chain reaction)}

\section{Reverse transcription}

$500 \mathrm{ng}$ of isolated RNA from each sample was reverse transcribed by Transcriptor High Fidelity cDNA Synthesis Kit (Roche Diagnostics GmbH, Mannheim, Germany) according to the protocol. As to the priming method, both anchored oligo(dT)18 and random hexamer primers were used.

qPCR (quantitative polymerase chain reaction)

2 technical and 2 biological replicates for each time point of the culture were used. qPCRs were performed on Light Cycler 480 Instrument II (Roche Diagnostics GmbH, Mannheim, Germany).

cDNA synthesized in reverse transcription served as a template. The components of the reaction mix were as follows: QUANTUM Eva Green PCR Kit (Syngen Biotech, Wroclaw, Poland) which was used as the master mix, the $10 \mu \mathrm{M}$ oligodeoxynucleotides which were purchased from Thermo Fisher Scientific (Thermo Fisher Scientific, Waltham, MA, USA) and are characterized in the table below (Tab. 1) and PCR-grade water. $9 \mu \mathrm{l}$ of the reaction mix and $1 \mu \mathrm{l}$ of the template were added to each, respective well on a 96-well plate. (LightCycler® 480 Multiwell Plates 96, Roche Diagnostics GmbH, Mannheim, Germa-

TABLE 1 Oligodeoxynucleotides designed to detect the expression levels of the studied genes

\begin{tabular}{c|c|c|c}
\hline $\begin{array}{c}\text { GENE } \\
\text { NAME }\end{array}$ & $\begin{array}{c}\mathbf{5}^{\prime} \rightarrow \mathbf{3} \text { 'SEQUENCE OF THE FORWARD } \\
\text { PRIMER }\end{array}$ & $\begin{array}{c}\mathbf{5}^{\prime \rightarrow} \mathbf{3} \text { 'SEQUENCE OF THE FORWARD } \\
\text { PRIMER }\end{array}$ & PRODUCT SIZE (BP) \\
\hline JHDM1D & TCCCTTCACCTACATTTTCTG & TGCCTGCCTCGCCACATC & 89 \\
\hline$P H F 2$ & CCATCGGTGCCAAGACAGG & GGGGAGGTGGTGTTAGGAG & 164 \\
\hline$P H F 8$ & CCCTCGCCATCATTCACTG & TTCTCCCTCTTCCCGCTGT & 146 \\
\hline
\end{tabular}

TABLE 2 Thermal profile of RT-qPCRs

\begin{tabular}{|c|c|c|c|c|}
\hline \multicolumn{2}{|c|}{ STEP } & TEMPERATURE $\left[{ }^{\circ} \mathrm{C}\right]$ & TIME [MIN] & NUMBER OF CYCLES \\
\hline \multicolumn{2}{|c|}{ Preincubation } & 95 & 600 & 1 \\
\hline \multirow{3}{*}{ Amplification } & Denaturation & 95 & 15 & \multirow{3}{*}{40} \\
\hline & Annealing & 58 & 15 & \\
\hline & Elongation & 72 & 15 & \\
\hline \multirow{4}{*}{\multicolumn{2}{|c|}{ Melting }} & 95 & 60 & \multirow{4}{*}{1} \\
\hline & & 40 & 60 & \\
\hline & & 70 & 1 & \\
\hline & & 95 & 1 & \\
\hline \multicolumn{2}{|c|}{ Cooling } & 37 & 30 & 1 \\
\hline
\end{tabular}


ny). The plate was sealed with a sealing foil (LightCycler ${ }^{\circledR} 480$ Sealing Foil, Roche Diagnostics GmbH, Mannheim, Germany) centrifuged at $1500 \mathrm{rpm}$ for 1 minute and placed in the thermocycler. The thermal profile of the reaction is presented in the table 2 .

The $2{ }^{-\Delta \Delta C}{ }_{T}$ method for relative gene expression analysis was applied [20]. cDNA synthesized from RNA isolated after $24 \mathrm{~h}$ of cell culture served as a control. The relative expression of the studied genes was normalized against the expression of two reference genes - GAPDH and ACTB.

The analyses and graphs were performed and prepared using $\mathrm{R}$ language and environment and Microsoft Excel (Microsoft Corporation) [21].

\section{Ethical approval}

The research related to human use has been complied with all the relevant national regulations, institutional policies and in accordance the tenets of the Helsinki Declaration, and has been approved by the Poznan University of Medical Sciences Bioethical Committee with the resolution no. 558/17.

\section{Informed consent statement}

Informed consent has been obtained from all individuals included in this study.

\section{Results}

In this study, relative normalized gene expression of three genes encoding histone demethylases, namely JHDM1D, PHF2 and PHF8, at six time points of the cell culture: after 48 h, 72 h, 96 h, 120 h, $144 \mathrm{~h}$ and $168 \mathrm{~h}$ in reference to $24 \mathrm{~h}$ was assessed.
It was observed that the expression levels of PHF2 was elevated in all time points of the culture, while the tendency of JHDM1D and PHF8 was mainly a decrease in expression.

The lowest expression was reported for JHDM1D at $120 \mathrm{~h}$ of culture duration $(\log (2) \mathrm{FC}$ of -2.78$)$. With the exception of $72 \mathrm{~h}, J H D M 1 D$ displayed a decrease in expression.

PHF8 also exhibited a decrease of expression level mainly but not as large as for JHDM1D. However, for cell culture after $96 \mathrm{~h}$ the expression level was close to control and for $72 \mathrm{~h}$ of culture duration was as follows: $\log (2) \mathrm{FC}=0.17$.

As described above PHF2 was the only gene for which the increase in expression was observed during all the time points of the culture, reaching $\log (2) \mathrm{FC}$ of 3.13 for $120 \mathrm{~h}$ of culture.

\section{Discussion}

Granulosa cells play crucial role in folliculogenesis. Besides hormonal secretory function, they participate in bidirectional communication with oocytes via connexins which form gap junctions and via paracrine signaling. In this cross-talk, the GCs are involved in the regulation of growth, development and transcriptional activity in the female gamete [22-24].

The stem cell research has evolved greatly in the last 50-60 years and the interest in studying cell populations with stem-like properties is growing increasingly. It has been reported that GCs may display stemness and transdifferentiation potential, as they express molecular markers characteristic

\section{Relative normalized gene expression}
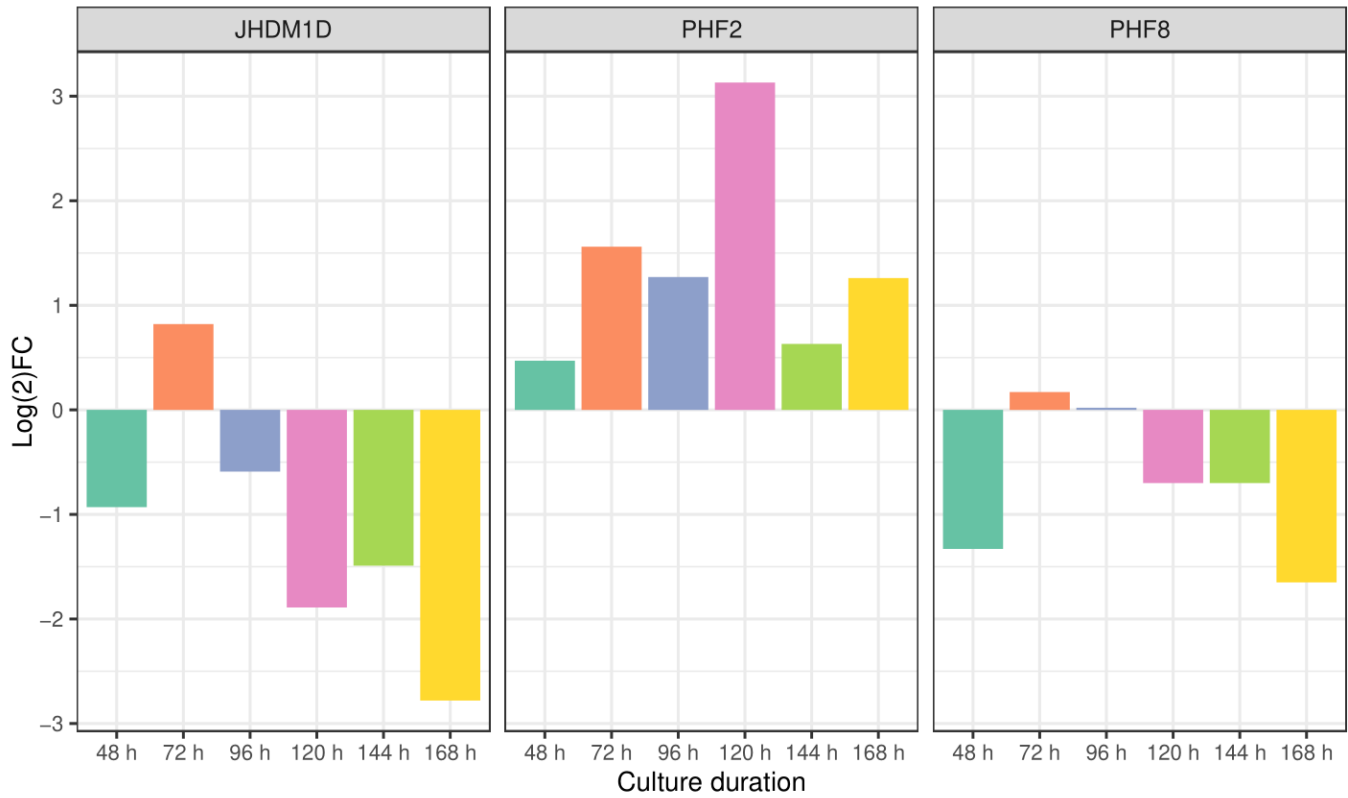

Culture duration

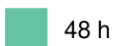

$72 \mathrm{~h}$

$96 \mathrm{~h}$

$120 \mathrm{~h}$

$144 \mathrm{~h}$

$168 \mathrm{~h}$

FIGURE 1 Relative normalized expression of JHDM1D, PHF2 and PHF8 in six time points of the human granulosa cell culture $(48 \mathrm{~h}, 72 \mathrm{~h}, 96 \mathrm{~h}, 120 \mathrm{~h}, 144 \mathrm{~h}$ and $168 \mathrm{~h})$. The values are presented as logarithm to the base 2 of the fold change (log(2) FC) of the tested culture duration vs. $24 \mathrm{~h}$ culture duration 
of stem cells: transcription factors such as OCT-4, NANOG and SOX-2, as well as MSC-specific cell surface markers, namely CD29, CD44, CD90, CD105, CD117, CD166 [6,17]. Furthermore, granulosa cells demonstrate high telomerase activity and have been shown to differentiate into i.e. neurogenic, chondrogenic and osteogenic lineages [6,25].

The establishment and determination of genetic and epigenetic changes in granulosa cells during cell culture is necessary for the future applications in fields such as organ reconstruction, tissue engineering as well as in cell-based therapy of female infertility [17].

Epigenetics is the study of heritable gene expression changes independent of DNA sequence $[12,13]$. Together with DNA methylation and miRNAs, histone modifications constitute one of the most studied hallmarks of epigenetic inheritance [26]. The $\mathrm{N}$-terminal tails of the histones may undergo posttranslational modifications (PTMs), which impact various molecular processes such as transcription, replication, and chromosome maintenance [27].

In this study, changes of transcript levels of genes JHDM1D, PHF2 and PHF8 which may affect the state of posttranslational modifications of histones were assessed.

Histone methylation is a key covalent histone modification in epigenetic regulation and occurs at lysine and arginine residues at histone tails [28]. It is implicated in both transcriptional activation and repression depending on position and methylation state. H3K4, H3K36 and H3K79 methylations confer active transcription, while $\mathrm{H} 3 \mathrm{~K} 9, \mathrm{H} 3 \mathrm{~K} 27$ and $\mathrm{H} 4 \mathrm{~K} 20$ methylations are considered to mark silenced chromatin states. There are three lysine methylation states-mono-, di- and trimethylation [29]. As to maintain proper cell fate and genomic stability, two classes of enzymes regulate the methylation of amino acid residues within histones: methyltransferases (KMTs) and demethylases (KDMs) [27].

Jumonji C domain containing histone demethylase 1 homolog D (JHDM1D, also known as KIAA1718 or KDM7A) is a member of the plant homeodomain (PHD) finger protein (PHF) family and thus possesses a single $\mathrm{N}$-terminal plant homeodomain (PHD) which participates in epigenetic regulation [30]. The Jumonji C domain is responsible for removal of the dimethylation of histone $\mathrm{H} 3$ lysine 9 and lysine 27 (H3K9me2 and H3K27me2, respectively), while PHD domain binds H3K4me3 and controls the rate of demethylation [31]. It has been reported that JHDM1D plays a tumor suppressive role by regulation of angiogenesis, may regulate neural differentiation and development in mammals and is upregulated during cardiomyocyte differentiation of mouse embryonic stem cells [31-33]. Furthermore, decreased expression of JHDM1D was found to be associated with preeclampsia through down-regulating HLA-G [14].
Histone demethylase plant homeodomain finger 2 (PHF2) is a dimethylated histone $\mathrm{H} 3$ lysine 9 (H3K9me2) demethylase that also recognizes histone trimethyl H3K4 (H3K4me3) through its PHD. It is described as a transcriptional activator [15]. It was demonstrated that PHF2 can demethylate H4K20me3 and is suggested to act on non-histone targets $[34,35]$. PHF2 displays high expression in embryonic neural tube and ganglia [36]. It is implicated in control of proinflammatory genes and act as a tumor suppressor through epigenetic regulation of p53 [37,38]. Recently, PHF2 was shown to promote DNA repair by homologous recombination by controlling CtIP-dependent resection of double strand breaks [15].

PHF8 demethylates monomethyl H4K20 (H4K20me1) with additional demethylase activities of H3K9me1 and H3K9me2. PHF8 can regulate neural development, and various mutations in PHF8 can lead to X-linked mental retardation, intellectual disability, autism and cleft lip/palate [16,39]. As reported by, this histone demethylase can bind more than one third of genes, nevertheless physiologically regulates only $2-5 \%$ of these targets [40]. Moreover, it has been demonstrated that PHF8 is involved in regulation of the G0/G1-to-S transition through interaction with E2F1, promote epithelial-to-mesenchymal transition and has also been reported to interact with MYC to regulate cytoskeletal dynamics in HeLa cells $[16,41,42]$.

Although there are no studies reporting expression pattern or functional implication of this particular enzymes in human granulosa cells to date, several reports demonstrate granulosa cell-specific expression and possible implications of epigenetic-modifying enzymes in regulation of follicullogenesis. A study by Krieg et al. aimed at the assessment of expression of two histone demethylases, namely KDM4A and KDM4B, in granulosa cells from patients undergoing in vitro fertilization. It was demonstrated that this two genes were differentially expressed in both cumulus and mural granulosa cells and a relation between pregnancy outcome and expression of both KDM4A and KDM4B mRNA in cumulus granulosa and mural cells was reported [43]. In another study, cell-specific and developmentally regulated patterns of histone H3 methylation at lysine 4 (K4) in porcine preovulatory follicles and during luteinization in pig ovaries were determined. It was demonstrated that H3K4 methylation in GCs was distribution and follicular stage-specific. Expression of lysine-specific demethylase 1 (LSD1 or KDM1) was corpus luteum-restricted [44]. Moreover, Guo et al. observed a cell-specific large-magnitude decrease in histone demethylase KDM1A in granulosa cells from ovaries of prenatal testosterone (T)-treated sheep and corresponding large-magnitude increase in SUV39H1, which is a histone methyltransferase [45]. 
In the present study we examined the expression levels of JHDM1D, PHF2 and PHF8 and observed their respective: tendency for downregulation with the exception of the time point of $72 \mathrm{~h}$ (JHDM1D), stating the repression of transcription, global, although not gradual upregulation (PHF2), which would suggest a transcriptional activation of targeted genes and downregulation trend with the exception of $72 \mathrm{~h}$ and $96 \mathrm{~h}$ time point (PHF8) which implies a situation similar as observed for JHDM1D. These results may point towards dynamic epigenetic changes in human granulosa cells during shortterm IVC.

\section{Conclusions}

In this study, an insight into the transcriptomic changes in human GCs during in vitro cultivation was provided. A tendency for decrease in expression of JHDM1D and PHF8 suggests repression of transcription, while the observed increase in PHF2 expression is associated with transcriptional activation of target genes. Further study on a larger population with the aim of target genes identification would be required in order to confirm and broaden the scope of the presented results.

\section{Acknowledgements}

This publication and its results are an outcome of a cooperation between Poznan University of Medical Sciences (Poznań, Poland) and Polish Ministry of Science and Higher Education, with Cellivia 3 SA (Poznań, Poland), as a part of the "Professional PhD" program.

\section{Corresponding author}

Dorota Bukowska, Department of Diagnostics and Clinical Sciences, Institute of Veterinary Medicine, Nicolaus Copernicus University in Toruń, Toruń, Poland, email: dbukowska@umk.pl.

\section{Conflict of interest statement}

The authors declare they have no conflict of interest.

\section{References}

1. Lai D, Xu M, Zhang Q Chen Y, Li T, Wang Q, Gao Y, Wei C. Identification and characterization of epithelial cells derived from human ovarian follicular fluid. Stem Cell Res Ther. 2015;6(1):13; DOI:10.1186/ s13287-015-0004-6.

2. Rodgers RJ, Irving-Rodgers HF. Formation of the ovarian follicular antrum and follicular fluid. Biol Reprod. 2010;82(6):1021-9; DOI:10.1095/ biolreprod.109.082941.

3. Wen X, Li D, Tozer AJ, Docherty SM, Iles RK. Estradiol, progesterone, testosterone profiles in human follicular fluid and cultured granulosa cells from luteinized pre-ovulatory follicles. Reprod Biol Endocrinol. 2010;8:117; DOI:10.1186/1477-7827-8-117.

4. Ernst EH, Franks S, Hardy K, Villesen P, Lykke-Hartmann K. Granulosa cells from human primordial and primary follicles show differential global gene expression profiles. Hum Reprod. 2018;33(4):666-679; DOI:10.1093/humrep/dey011.

5. Alam MH, Miyano T. Interaction between growing oocytes and granulosa cells in vitro. Reprod Med Biol. 2020;19(1):13-23; D0I:10.1002/ rmb2.12292.

6. Kossowska-Tomaszczuk K, De Geyter C, De Geyter M, Martin I, Holzgreve W, Scherberich A, Zhang H. The Multipotency of Luteinizing Granulosa Cells Collected from Mature Ovarian Follicles. Stem Cells. 2009;27(1):210-9; DOI:10.1634/stemcells.2008-0233.

7. Hoang SN, Ho CNQ Nguyen TTP, Doan CC, Tran DH, Le LT. Evaluation of stemness marker expression in bovine ovarian granulosa cells. Anim Reprod. 2019;16(2):277-81; DOI:10.21451/1984-3143-AR2018-0083.

8. Kranc W, Brązert M, Celichowski P, Bryja A, Nawrocki MJ, Ożegowska K, Jankowski M, Jeseta M, Pawelczyk L, Bręborowicz A, Rachoń D,
Skowroński MT, Bruska M, Zabel M, Nowicki M, Kempisty B. 'Heart development and morphogenesis' is a novel pathway for human ovarian granulosa cell differentiation during long-term in vitro cultivation-a microarray approach. Mol Med Rep. 2019;19(3):1705-15; DOI:10.3892/ mmr.2019.9837.

9. Brevini TAL, Pennarossa G, Rahman MM, Paffoni A, Antonini S, Ragni G, deEguileor M, Tettamanti G, Gandolfi F. Morphological and Molecular Changes of Human Granulosa Cells Exposed to 5-Azacytidine and Addressed Toward Muscular Differentiation. Stem Cell Rev Reports. 2014;10(5):633-42; DOI:10.1007/s12015-014-9521-4.

10. Murry CE, Keller G. Differentiation of Embryonic Stem Cells to Clinically Relevant Populations: Lessons from Embryonic Development. Cell. 2008;132(4):661-80; DOI:10.1016/j.cell.2008.02.008.

11. Das BC, Tyagi A. Stem Cells: A Trek from Laboratory to Clinic to Industry. In: Ashish Verma S, Singh A, editors. Animal Biotechnology. UK, USA: Academic Press, an imprint of Elsevier Inc.; 2014. Chapter 23. Pages 425-50; DOI:10.1016/B978-0-12-416002-6.00023-7.

12. Sharma S, Kelly TK, Jones PA. Epigenetics in cancer. Carcinogenesis 2010;31(1): 27-36; DOI:10.1093/carcin/bgp220.

13. Wolffe AP, Matzke MA. Epigenetics: Regulation through repression. Science. 1999;286(5439):481-6; DOI:10.1126/science.286.5439.481.

14. Luo S, Pei J, Li X, Gu W. Decreased expression of JHDMID in placenta is associated with preeclampsia through HLA-G. J Hum Hypertens. 2018;32(6):448-54; DOI:10.1038/s41371-018-0062-1.

15. Alonso-de Vega I, Paz-Cabrera MC, Rother MB, Wiegant WW, Checa-Rodríguez C, Hernández-Fernaud JR, Huertas P, Freire R, van Attikum H, Smits VAJ. PHF2 regulates homology-directed DNA repair by controlling the resection of DNA double strand breaks. Nucleic Acids Res. 2020;48(9):4915-27; DOI:10.1093/nar/gkaa196.

16. Shao P, Liu Q Maina PK, Cui J, Bair TB, Li T, Umesalma S, Zhang W, Qi HH. Histone demethylase PHF8 promotes epithelial to mesenchymal transition and breast tumorigenesis. Nucleic Acids Res. 2017;45(4):1687702; DOI:10.1093/nar/gkw1093.

17. Dzafic E, Stimpfel M, Virant-Klun I. Plasticity of granulosa cells: On the crossroad of stemness and transdifferentiation potential. J Assist Reprod Genet. 2013;30(10):1255-61; D0I:10.1007/s10815-013-0068-0.

18. Ferraretti AP, La Marca A, Fauser BCJM, Tarlatzis B, Nargund G, Gianaroli L. ESHRE consensus on the definition of 'poor response' to ovarian stimulation for in vitro fertilization: The Bologna criteria. Hum Reprod. 2011;26(7):1616-24; DOI:10.1093/humrep/der092.

19. Chomczynski P, Sacchi N. Single-step method of RNA isolation by acid guanidinium thiocyanate-phenol-chloroform extraction. Anal Biochem. 1987;162(1):156-9; DOI:10.1016/0003-2697(87)90021-2.

20. Livak KJ, Schmittgen TD. Analysis of relative gene expression data using real-time quantitative PCR and the 2(-Delta Delta C(T)) Method. Methods. 2001;25(4):402-8; DOI:10.1006/meth.2001.1262.

21. R Core Team (2020). R: A language and environment for statistical computing. R A Lang Environ Stat Comput R Found Stat Comput Vienna, Austria. 2020.

22. Richards JS, Pangas SA. The ovary: Basic biology and clinical implications. J Clin Invest. 2010;120(4):963-72; DOI:10.1172/JCI41350.

23. Kempisty B, Ziółkowska A, Ciesiółka S, Piotrowska H, Antosik P, Bukowska D, Nowicki M, Brüssow KP, Zabel M. Study on connexin gene and protein expression and cellular distribution in relation to real-time proliferation of porcine granulosa cells. J Biol Regul Homeost Agents. 2014;28(4):625-35

24. Kidder GM, Vanderhyden BC. Bidirectional communication between oocytes and follicle cells: Ensuring oocyte developmental competence. Can J Physiol Pharmacol. 2010;88(4):399-413; DOI:10.1139/Y10-009.

25. Russo V, Berardinelli P, Martelli A, Di Giacinto O, Nardinocchi D, Fantasia D, Barboni B. Expression of telomerase reverse transcriptase subunit (TERT) and telomere sizing in pig ovarian follicles. J Histochem Cytochem. 2006;54(4):443-55; DOI:10.1369/jhc.4A6603.2006

26. Costa-Reis P, Sullivan KE. Genetics and epigenetics of systemic lupus erythematosus. Curr Rheumatol Rep. 2013;15(9):369; DOI:10.1007/ s11926-013-0369-4.

27. Black JC, Van Rechem C, Whetstine JR. Histone Lysine Methylation Dynamics: Establishment, Regulation, and Biological Impact. Mol Cell. 2012;48(4):491-507; DOI:10.1016/j.molcel.2012.11.006.

28. Shi YG, Tsukada Y. The discovery of histone demethylases. Cold Spring Harb Perspect Biol. 2013;5(9):a017947; DOI:10.1101/cshperspect. a017947.

29. Hyun K, Jeon J, Park K, Kim J. Writing, erasing and reading histone lysine methylations. Exp Mol Med. 2017;49(4):e324; DOI:10.1038/ emm.2017.11.

30. Tsukada YI, Fang J, Erdjument-Bromage $\mathrm{H}$, Warren ME, Borchers $\mathrm{CH}$ Tempst P, Zhang Y. Histone demethylation by a family of JmjC domain-containing proteins. Nature. 2006;439(7078):811-6; DOI:10.1038/ nature 04433. 
31. Tsukada YI, Ishitani T, Nakayama KI. KDM7 is a dual demethylase for histone H3 Lys 9 and Lys 27 and functions in brain development. Genes Dev. 2010;24(5):432-7; DOI:10.1101/gad.1864410.

32. Osawa T, Muramatsu M, Wang F, Tsuchida R, Kodama T, Minami T, Shibuya M. Increased expression of histone demethylase JHDM1D under nutrient starvation suppresses tumor growth via down-regulating angiogenesis. Proc Natl Acad Sci U S A. 2011;108(51):20725-9; DOI:10.1073/pnas.1108462109.

33. Tang Y, Chen ZY, Hong YZ, Wu Q Lin HQ Chen CD, Yang HT. Expression profiles of histone lysine demethylases during cardiomyocyte differentiation of mouse embryonic stem cells. Acta Pharmacol Sin 2014;35(7):899-906; DOI:10.1038/aps.2014.40.

34. Okuno Y, Ohtake F, Igarashi K, Kanno J, Matsumoto T, Takada I, Kato S, Imai Y. Epigenetic regulation of adipogenesis by PHF2 histone demethylase. Diabetes. 2013;62(5):1426-34; DOI:10.2337/db12-0628.

35. Baba A, Ohtake F, Okuno Y, Yokota K, Okada M, Imai Y, Ni M, Meyer CA, Igarashi K, Kanno J, Brown M, Kato S. PKA-dependent regulation of the histone lysine demethylase complex PHF2-ARID5B. Nat Cell Biol. 2011;13(6):668-75; DOI:10.1038/ncb2228

36. Hasenpusch-Theil K, Chadwick BP, Theil T, Heath SK, Wilkinson DG, Frischauf AM. PHF2, a novel PHD finger gene located on human Chromosome 9q22. Mamm Genome. 1999;10(3):294-8; DOI:10.1007/ s003359900989.

37. Stender JD, Pascual G, Liu W, Kaikkonen MU, Do K, Spann NJ, Boutros M, Perrimon N, Rosenfeld MG, Glass CK. Control of Proinflammatory Gene Programs by Regulated Trimethylation and Demethylation of Histone H4K20. Mol Cell. 2012;48(1):28-38; DOI:10.1016/j.molcel.2012.07.020.

38. Lee KH, Park JW, Sung HS, Choi YJ, Kim WH, Lee HS, Chung HJ, Shin HW Cho CH, Kim TY, Li SH, Youn HD, Kim SJ, Chun YS. PHF2 histone demethylase acts as a tumor suppressor in association with p53 in cancer. Oncogene. 2015;34(22):2897-909; DOI:10.1038/onc.2014.219.

39. Laumonnier F, Holbert S, Ronce N, Faravelli F, Lenzner S, Schwartz CE Lespinasse J, Van Esch H, Lacombe D, Goizet C, Tuy FPD, Van Bokhoven H, Fryns JP, Chelly J, Ropers HH, Moraine C, Hamel BCJ, Briault S. Mutations in PHF8 are associated with X linked mental retardation an cleft lip/cleft palate. J Med Genet. 2005;72(1):19-22; DOI:10.1136/ jmg.2004.029439.

40. Qi HH, Sarkissian M, Hu GQ, Wang Z, Bhattacharjee A, Gordon DB, Gonzales M, Lan F, Ongusaha PP, Huarte M, Yaghi NK, Lim H, Garcia BA, Brizuela L, Zhao K, Roberts TM, Shi Y. Histone H4K20/H3K9 demethylase PHF8 regulates zebrafish brain and craniofacial development. Nature. 2010;466(7305):503-7; DOI:10.1038/nature09261.

41. Liu W, Tanasa B, Tyurina O V., Zhou TY, Gassmann R, Liu WT, Ohgi KA, Benner C, Garcia-Bassets I, Aggarwal AK, Desai A, Dorrestein PC, Glass CK, Rosenfeld MG. PHF8 mediates histone H4 lysine 20 demethylation events involved in cell cycle progression. Nature. 2010;466(7305):508512; DOI:10.1038/nature09272.

42. Asensio-Juan E, Gallego C, Martínez-Balbás MA. The histone demethylase PHF8 is essential for cytoskeleton dynamics. Nucleic Acids Res. 2012;40(19):9429-40; DOI:10.1093/nar/gks716.

43. Krieg AJ, Mullinax SR, Grimstad F, Marquis K, Constance E, Hong Y, Krieg SA, Roby KF. Histone demethylase KDM4A and KDM4B expression in granulosa cells from women undergoing in vitro fertilization. J Assist Reprod Genet. 2018;35(6):993-1003; DOI:10.1007/s10815-018-1151-3.

44. Seneda MM, Godmann M, Murphy BD, Kimmins S, Bordignon V. Developmental regulation of histone $\mathrm{H} 3$ methylation at lysine 4 in the porcine ovary. Reproduction. 2008;135(6):829-38; DOI:10.1530/REP-07-0448.

45. Guo X, Puttabyatappa M, Thompson RC, Padmanabhan V. Developmental Programming: Contribution of Epigenetic Enzymes to Antral Follicular Defects in the Sheep Model of PCOS. Endocrinology. 2019;160(10):24712484; DOI:10.1210/en.2019-00389. 